\title{
Physical activity, fatigue and quality of life during a clinical adjuvant treatment of breast cancer: a comparative study
}

\author{
Leonessa Boing ${ }^{1 *}$, Tatiana de Bem Fretta ${ }^{1}$, Melissa de Carvalho Souza Vieira ${ }^{1}$, Luiza \\ Andreatta Denig ${ }^{1}$, Anke Bergmann ${ }^{2}$, Adriana Coutinho de Azevedo Guimarães ${ }^{1}$

\begin{abstract}
The objective of the study was to compare the physical activity, fatigue and quality of life of patients during breast cancer treatment and to investigate the association between these variables. It was included 122 women in clinical treatment at the Cancer Research Center (CEPON) in Florianópolis, SC. We used a questionnaire with general information, physical activity (IPAQ - short), fatigue (Piper fatigue) and quality of life (EORTC QLQ - C30). One-way ANOVA with Scheffe's post-hoc, Chi-square, and univariate and multiple linear regression $(p<0.05)$ were used. It was observed a greater walking time and total physical activity for the patients in the hormone therapy. In the fatigue, worse scores were presented by the patients in the chemotherapy. In the quality of life, there was a difference in the symptomatic scale, with worse scores on the subscales of nausea and vomiting, pain and loss of appetite for patients on chemotherapy and constipation for radiotherapy. It was identified an association between the increase of the physical activity with the improvement of the physical, social function and symptoms of the fatigue, regardless of the type of treatment or age. Patients in the hormone therapy practiced more physical activity, and those in chemotherapy had worse side effects. It is necessary to encourage physical activity during treatment, since benefits in quality of life and fatigue are evidenced.

Keywords: motor activity, breast neoplasm, quality of life.
\end{abstract}

\section{INTRODUCTION}

Breast cancer represents the most frequent type of neoplasm in women worldwide, and in 2012, 1.7 million cases were diagnosed, representing an incidence of $25 \%$, with an estimated 500.000 deaths (American Cancer Society, 2015). According to data from the World Health Organization in Brazil, this type of cancer is the major responsible for mortality rates, behind only cardiovascular diseases (Instituto Nacional do Câncer [INCA], 2015). For the biennium 2016 and 2017, 57.960 new cases of breast cancer are expected in Brazil, with an estimated risk of 56.20 cases per 100.000 women (INCA, 2016).

Treatment options for breast cancer include surgery, whether combined with chemotherapy, radiation therapy and hormone therapy, which can be performed on neoadjuvant (before surgery) or adjuvant (after surgery) (World
Health Organization [WHO], 2014). Chemotherapy and hormone therapy have as their main purpose the systemic control of the disease and the surgery and radiotherapy, the local control (Lobô, 2014; INCA, 2014).

Because of these treatments, the patient presents possible side effects such as alopecia, nausea, vomiting, pain, depression and decreased self-esteem (Batista et al., 2014; Cardoso, Nicolussi, Okino, \& Sawada, 2009). Another symptom present is fatigue, which has a subjective and multidimensional concept, classified in physical (need to rest and lack of energy), cognitive (low concentration or attention) and affective (drop in motivation and interest); in which breast cancer patients report the same as chronic, unpleasant, stressful and limiting daily activities (Bleijemberga, Servaes, \& Verhagenb, 2002). Due to this context, the quality of life of these patients declines, and may

\footnotetext{
Manuscript received at January $15^{\text {th }} 2018$; Accepted at July $12^{\text {th }} 2018$

${ }^{1}$ Santa Catarina State University, Florianopolis, Brazil.

${ }^{2}$ National Cancer Institute, INCA, Rio de Janeiro, Brazil.

* Corresponding author: leonessaboing@gmail.com
} 
influence social and emotional aspects, mainly due to the side effects of their treatment (Bezerra, 2013; Mohammadi, Sulaiman, Koon, Amani, \& Hosseini, 2013).

These side effects can sometimes be minimized through healthy living habits such as a balanced diet and the practice of physical activity (Macedo et al., 2011). Since physical activity after treatment improves cardiorespiratory capacity and cardiovascular function, as well as body composition (increased muscle mass and loss of fat mass), immune function, strength and flexibility, body image, self-esteem, and mood; can also reduce the number and severity of its side effects such as nausea, fatigue, pain, stress, depression and anxiety (Buffart, 2012; Galvão, Hayes, Newton, \& Spence, 2009). Thus, the main objective of rehabilitation programs for women diagnosed with breast cancer is to improve their quality of life, with body weight control, in a correct and healthy body composition, increasing cardiorespiratory function, muscular strength and endurance, preserving the neuromuscular integrity, and with this, diminishing the perception and fatigue (Galanti, Klika, \& Stefani, 2017).

Cancer has become a major public health concern. (Andrade \& Duarte, 2003), and the development of treatments; for which early detection made it possible to increase emphasis on quality of life and a greater range of survival (Anjos, 2002). In relation to the studies that investigate the physical activity in breast cancer, most of them focus on patients during the posttreatment period (Boing et al., 2016). Therefore, it is essential to verify the practice of physical activity during clinical treatment, seeking to minimize and prevent its negative effects, as well as, investigate the quality of life and fatigue and their behavior in the different treatments. Thus, the objective of the present study was to compare the physical activity, fatigue and quality of life of patients during chemotherapy, radiotherapy and hormone therapy for breast cancer, as well as to investigate the association between these variables.

\section{METHOD}

Cross-sectional, analytical study. Project approved by the Committee on Ethics in Research in Human Beings (CEPSH) of UDESC, protocol no. 688.548 and by the Research Ethics Committee of CEPON (CEP), protocol no. 818.174.

\section{Participants}

The study included 122 women diagnosed with breast cancer who were in adjuvant treatment at the Oncology Research Center (CEPON), being 46 in chemotherapy, 24 in radiotherapy and 42 in hormone therapy. The sample size was calculated using the software G*Power 3.1.9.2 (Faul, Erdfelder, Lang, \& Buchner, 2007), to which the following criteria were considered: significance level of $5 \%$, test power of $95 \%$ and effect size of 0.30 ; Thus, 111 subjects were suggested for this study. The inclusion criteria established for the study were: age range from 40 to 80 years; at any stage of adjuvant clinical treatment, namely chemotherapy, radiotherapy or hormone therapy. Those with breast cancer stage IV were excluded.

\section{Measures}

The questionnaire for the individual interview was initially composed of the block of demographic and clinical information, followed by the block of physical activity, fatigue and quality of life. Demographic information was characterized by age, marital status and economic class, and clinical status, weight status, comorbidities associated with cancer, surgery and physical therapy. All this information was selfreported by the patients. The economic level was obtained by the IBGE criterion (2010), which stratifies in economic strata $\mathrm{A}, \mathrm{B}, \mathrm{C}, \mathrm{D}$ and $\mathrm{E}$, based on the number of minimum wages ( $R \$ 724.00$ - 2014) in monthly family income. In the analyzes of the present study, it was adhered to the categories: medium or high economic level (A, B and C); and low economic level (D and E). The weight status was obtained by calculating the Body Mass Index (BMI), and categorized according to the WHO (2004): leanness (BMI $<18.5$ ); eutrophy (IMC 18.5-24.9); overweight (IMC 25.0-29.9); pre-obesity and obesity 
$(\mathrm{BMI} \geq 30.0)$. For the statistical analyzes of this study, the categories in normal weight (leanness and eutrophy) and overweight (overweight, preobesity and obesity) were used.

Physical activity was investigated by International Physical Activity Questionnaire IPAQ short version (Pardini et al., 1997). The Brazilian reproducibility was made by Matsudo et al. (2001) and showed significant and high Spearman correlation $(r h o=0.69-0.71: p<0.01)$, as validity of 0.75 in comparison with the Computer Science \& Aplications (CSA). This questionnaire contains six items that aim to investigate the number of times the subject has practiced at least 10 continuous minutes of walking, moderate and vigorous physical activity in the last week, in various engagements, namely, work, domestic, leisure, recreational and sporty.

Fatigue was investigated using the Piper Fatigue Scale (PFS), validated for patients after breast cancer diagnosis (Piper et al., 1998), with a Cronbach alpha of 0.97 . The Brazilian validation in cancer patients showed a Cronbach alpha of 0.84 to 0.94 for the whole scale (Mota, Pimenta, \& Piper, 2009). With 22 items distributed in three dimensions: behavioural (items 2 to 7 ) with relation to the funciontal capacity, including personal issues, social activities and sexual relationship; affective (items 8 to 12) which seeks to find the meaning attributed to fatigue; sensory/psychological (items 13 to 23) which identifies components of self-perception, emotional and cognitive in the presence of fatigue. Each item is scored in a numeral scale (0 to 10). Domain scores and total scores range from 0 to 10 and are obtained by summing the score of each item and dividing it by the number of items in each domain, or by 22 , when calculating the total score. The near to 10 , the greater the level of patient fatigue.

To determine the quality of life of the patients, the questionnaire European Organization for Research and Treatment of Cancer Quality of Life Questionnaire C30 - EORTC QLQ - C30 (Aaronson et al., 1993) was choosen. It has validation in Brazil by Michels, Latorre, e Maciel (2013), with Cronbach alpha of 0.72 to the global health scale, 0.86 to the functional scale and 0.81 to the symptomatic scale. Contain 30 items which evaluate the quality of life of cancer patients in the 4 past weeks, and divide in three scales: Global health scale, Functional scale with the subscales of: physical, functional, emotional, social and cognitive, and Symptomatic scale with the subscales: fatigue, pain and nausea / vomiting, dyspnea, insomnia, loss of appetite, constipation, diarrhea and financial difficulties. The answers are presented in the form of Likert scale according to the classification: 1 - no, 2 little, 3 - moderately and 4 - very.

The only exceptions apply to the global health scale. This is composed of two questions that ask the patient to rate both their health and their quality of life in the last week, in a grade of 1 to 7. In this case, 1 would be a poor quality of life and 7 a good quality of life. Scores range from 0 to 100 , and it is determined that for the functional and overall health scales, the nearest 100 is indicative of a better quality of life. Differently, for the symptomatic scale, the closest value of 100 is indicative of a worse quality of life, since it determines a greater presence of symptoms.

\section{Procedures}

All participants were invited to voluntarily participate and written informed consent was obtained from all individual participants included in the study. The data collection was performed using a structured questionnaire that was provided to participants in individual interviews by three female trained researchers, and the mean time of the interviews was approximately 30 minutes. Contacts with the patients were made inside the Research Center in the following wards: chemotherapy, radiotherapy, physiotherapy, and in the waiting room of the doctor's offices and exam rooms.

\section{Statistical analysis}

Descriptive analysis was performed by mean and standard deviation, for quantitative variables, and absolute and relative frequency for qualitative variables. To evaluate the difference between the means by type of adjuvant treatment, the ANOVA test and the comparison by the Scheffe test were performed. For the qualitative variables, the difference was analyzed by the Chi- 
square test and the difference by the $\mathrm{Z}$ test. The association between physical activity, fatigue and health-related quality of life was assessed by univariate linear regression and the adjustment by age and type of treatment, by multiple linear regression. For all analyzes, $\mathrm{p}<0.05$ was considered statistically significant. Statistical package SPSS 23.0 was used.

Table 1

Demographic and clinical characteristics of breast cancer patients according to the adjuvant treatment in CEPON. Florianopolis - SC. $(n=122)$

\begin{tabular}{|c|c|c|c|c|c|c|}
\hline & Total n (\%)* & $\begin{array}{c}\text { CT (A) } \\
(\mathrm{n}=46) \\
\mathrm{n}(\%)^{* *}\end{array}$ & $\begin{array}{l}\mathrm{RT}(\mathrm{B}) \\
(\mathrm{n}=34) \\
\mathrm{n}(\%)^{* *}\end{array}$ & $\begin{array}{l}\operatorname{HMT}(\mathrm{C}) \\
(\mathrm{n}=42) \\
\mathrm{n}(\%)^{* *}\end{array}$ & $\begin{array}{r}\text { Difference in } \\
\text { the categories } \\
* * *\end{array}$ & $\mathrm{P}$ value \# \\
\hline Age (years old) & & & & & & 0.237 \\
\hline Mean (SD) & $55.0(9.1)$ & $53.3(8.9)$ & $55.4(8.9)$ & $56.6(9.6)$ & $\mathrm{A}=\mathrm{B}=\mathrm{C}$ & \\
\hline Marital status & & & & & & 0.151 \\
\hline Without partner & $56(45.9)$ & $26(46.4)$ & $12(21.4)$ & $18(32.1)$ & $\mathrm{A}=\mathrm{B}=\mathrm{C}$ & \\
\hline With partner & $66(54.1)$ & $20(30.3)$ & $22(33.3)$ & $24(36.4)$ & $\mathrm{A}=\mathrm{B}=\mathrm{C}$ & \\
\hline Economic level & & & & & & 0.273 \\
\hline $\begin{array}{l}\text { Middle or High (A, B, } \\
\text { C) }\end{array}$ & $20(16.4)$ & $06(30.0)$ & $04(20.0)$ & $10(50.0)$ & $\mathrm{A}=\mathrm{B}=\mathrm{C}$ & \\
\hline Low (D and E) & $102(83.6)$ & $40(39.2)$ & $30(29.4)$ & $32(31.4)$ & $\mathrm{A}=\mathrm{B}=\mathrm{C}$ & \\
\hline Weight status & & & & & & 0.501 \\
\hline Normal weight & $33(27.3)$ & $15(45.5)$ & $09(27.3)$ & $09(27.3)$ & $\mathrm{A}=\mathrm{B}=\mathrm{C}$ & \\
\hline Overweight & $88(72.7)$ & $31(35.2)$ & $24(27.3)$ & $33(37.5)$ & $\mathrm{A}=\mathrm{B}=\mathrm{C}$ & \\
\hline Comorbidities & & & & & & 0.435 \\
\hline Yes & $54(44.3)$ & $17(31.5)$ & $16(29.6)$ & $21(38.9)$ & $\mathrm{A}=\mathrm{B}=\mathrm{C}$ & \\
\hline No & $68(55.7)$ & $29(42.6)$ & $18(26.5)$ & $21(30.9)$ & $\mathrm{A}=\mathrm{B}=\mathrm{C}$ & \\
\hline Surgery type & & & & & & 0.281 \\
\hline Radical mastectomy & $70(57.4)$ & $23(32.9)$ & $19(27.1)$ & $28(40.0)$ & $\mathrm{A}=\mathrm{B}=\mathrm{C}$ & \\
\hline Conservative surgery & $52(42.6)$ & $23(44.2)$ & $15(28.8)$ & $14(26.9)$ & $\mathrm{A}=\mathrm{B}=\mathrm{C}$ & \\
\hline Physiotherapy & & & & & & 0.001 \\
\hline Yes & $53(43.4)$ & $15(28.3)$ & $10(18.9)$ & $28(52.8)$ & $\mathrm{A}=\mathrm{B}<\mathrm{C}$ & \\
\hline No & $69(56.6)$ & $31(44.9)$ & $24(34.8)$ & $14(20.3)$ & $\mathrm{A}=\mathrm{B}>\mathrm{C}$ & \\
\hline
\end{tabular}

Note. ${ }^{*}$ Percentage in the column; ${ }^{* *}$ Percentage in line; ${ }^{* *} \mathrm{Z}$ test; \# Chi-square test; $\mathrm{CT}=$ Chemotherapy; RT = Radiotherapy; HMT $=$ Hormone Therapy.

\section{RESULTS}

The mean age was 55 years ( \pm 9.1 years), the majority lived with a partner $(54.1 \%)$, low economic level (83.6\%), overweight (72.7\%) and had undergone radical mastectomy surgery (57.4\%). Differences were found only in the demographic and clinical variables in relation to the practice of previous physiotherapy, and a higher frequency was observed among those submitted to hormone therapy $(\mathrm{p}=0.001)$ (Table 1).

The comparison between the physical activity, fatigue and quality of life scores according to the adjuvant treatment is presented in Table 2 . Regarding physical activity, it was observed a higher walking score $(\mathrm{p}=0.018)$ and total physical activity $(p=0.009)$ for those patients who were being treated with hormone therapy. When assessing fatigue, for all domains analyzed, higher scores were demonstrated for those patients undergoing chemotherapy $(p=0.007)$. Considering the quality of life related to health, no difference was observed in the functional scales. On the symptomatic scale, the worst score was observed for those on chemotherapy, followed by hormone therapy and radiotherapy ( $\mathrm{p}$ $=0.002$ ). For nausea and vomiting, worse scores were obtained by patients undergoing chemotherapy, radiotherapy and hormone therapy, respectively $(\mathrm{p}=0.005)$. Pain $(\mathrm{p}=$ $0.041)$ and loss of appetite $(p=0.033)$ were worse for those on chemotherapy. Radiotherapy patients presented worse constipation score $(\mathrm{p}=$ 0.010).

Table 3 shows the association between total physical activity with fatigue and health-related quality of life. There was no association between physical activity and fatigue scores. Regarding 
quality of life, after adjustment for age and type of treatment, was found an increase of 0.5 points in the physical function score $(\mathrm{p}=0.009)$ and 0.3 points in the social function $(p=0.028)$. For the symptomatic scale, with each one-minute increase in the level of physical activity, a reduction of 0.35 in the fatigue score was observed $(p=0.008)$.

Table 2

Comparison of physical activity intensities, fatigue and quality of life of breast cancer patients according to the adjuvant treatment at CEPON. Florianopolis - SC. $(n=122)$

\begin{tabular}{|c|c|c|c|c|c|c|}
\hline \multirow{3}{*}{ Variables } & \multirow{3}{*}{$\begin{array}{c}\text { Total } \\
\text { Mean (SD) }\end{array}$} & \multicolumn{3}{|c|}{ Adjuvant treatment } & \multirow{3}{*}{$\begin{array}{c}\text { Difference in } \\
\text { categories* }\end{array}$} & \multirow{3}{*}{$\mathrm{P}$ value** } \\
\hline & & \multicolumn{3}{|c|}{ Mean (SD) } & & \\
\hline & & $\begin{array}{c}\text { CT (A) } \\
(\mathrm{n}=46)\end{array}$ & $\begin{array}{c}\text { RT (B) } \\
(\mathrm{n}=34)\end{array}$ & $\begin{array}{l}\text { HMT (C) } \\
(\mathrm{n}=42)\end{array}$ & & \\
\hline $\begin{array}{c}\text { Physical } \\
\text { (min/day) }\end{array}$ & & & & & & \\
\hline Walking & $15.9(15.9)$ & $11.3(17.6)$ & $11.5(21.7)$ & $24.6(31.2)$ & $\mathrm{A}=\mathrm{B}<\mathrm{C}$ & 0.018 \\
\hline Moderate PA & $9.5(27.1)$ & $5.6(27.8)$ & $5.1(15.3)$ & $17.1(32.2)$ & $\mathrm{A}=\mathrm{B}=\mathrm{C}$ & 0.076 \\
\hline Vigorous PA & $1.6(9.4)$ & $1.3(8.8)$ & $0.3(1.7)$ & $2.9(12.9)$ & $\mathrm{A}=\mathrm{B}=\mathrm{C}$ & 0.485 \\
\hline Moderate + Vigorous PA & $11.0(31.9)$ & $6.9(36.3)$ & $5.4(15.9)$ & $20.0(35.1)$ & $\mathrm{A}=\mathrm{B}=\mathrm{C}$ & 0.077 \\
\hline Total PA & $27.0(46.8)$ & $18.3(46.6)$ & $16.9(30.9)$ & $44.6(53.0)$ & $\mathrm{A}=\mathrm{B}<\mathrm{C}$ & 0.009 \\
\hline \multicolumn{7}{|l|}{ Fatigue } \\
\hline Total & $3.4(2.9)$ & $4.0(2.8)$ & $2.1(2.4)$ & $3.6(3.1)$ & $A=C>B$ & 0.010 \\
\hline Behavioral & $3.6(3.2)$ & $4.2(3.2)$ & $2.4(2.7)$ & $4.0(3.4)$ & $A=C>B$ & 0.036 \\
\hline Affective & $3.2(3.4)$ & $3.9(3.3)$ & $2.0(2.7)$ & $3.5(3.9)$ & $A=C>B$ & 0.050 \\
\hline Psychologic/Sensory & $3.2(2.8)$ & $3.9(2.7)$ & $2.0(2.6)$ & $3.5(2.9)$ & $\mathrm{A}=\mathrm{C}>\mathrm{B}$ & 0.007 \\
\hline \multicolumn{7}{|l|}{ EORTC-C30 } \\
\hline Global health status*** & $73.0(26.2)$ & $69.0(26.0)$ & $76.5(27.6)$ & $74.8(25.3)$ & $\mathrm{A}=\mathrm{B}=\mathrm{C}$ & 0.399 \\
\hline Functional scale*** & $65.4(21.3)$ & $62.1(23.2)$ & $69.1(20.1)$ & $66.0(20.1)$ & $\mathrm{A}=\mathrm{B}=\mathrm{C}$ & 0.336 \\
\hline Physical function & $66.9(21.0)$ & $66.5(21.3)$ & $68.0(22.5)$ & $66.3(19.6)$ & $\mathrm{A}=\mathrm{B}=\mathrm{C}$ & 0.931 \\
\hline Role performance & $64.1(36.9)$ & $58.7(38.8)$ & $67.6(38.0)$ & $67.1(33.9)$ & $\mathrm{A}=\mathrm{B}=\mathrm{C}$ & 0.459 \\
\hline Emotional function & $59.2(34.0)$ & $51.6(34.0)$ & $68.1(32.2)$ & $60.3(34.3)$ & $\mathrm{A}=\mathrm{B}=\mathrm{C}$ & 0.096 \\
\hline Cognitive function & $62.8(34.4)$ & $57.6(35.9)$ & $73.5(25.3)$ & $59.9(37.7)$ & $\mathrm{A}=\mathrm{B}=\mathrm{C}$ & 0.097 \\
\hline Social function & $78.0(29.9)$ & $79.7(27.0)$ & $71.1(34.9)$ & $81.7(28.2)$ & $\mathrm{A}=\mathrm{B}=\mathrm{C}$ & 0.269 \\
\hline Symptomatic scale & $31.0(23.1)$ & $40.1(24.5)$ & $22.9(18.4)$ & $27.6(22.0)$ & $\mathrm{B}<\mathrm{C}<\mathrm{A}$ & 0.002 \\
\hline Fatigue & $42.0(35.4)$ & $51.0(35.2)$ & $36.3(34.2)$ & $36.8(35.4)$ & $\mathrm{A}=\mathrm{B}=\mathrm{C}$ & 0.092 \\
\hline Nausea and vomit & $15.8(26.3)$ & $25.7(30.4)$ & $10.3(23.6)$ & $9.5(20.2)$ & $\mathrm{C}<\mathrm{B}<\mathrm{A}$ & 0.005 \\
\hline Pain & $39.7(39.2)$ & $51.1(40.0)$ & $30.9(36.5)$ & $34.5(38.3)$ & $\mathrm{B}=\mathrm{C}<\mathrm{A}$ & 0.041 \\
\hline Dyspnea & $11.7(27.7)$ & $18.1(33.5)$ & $5.9(19.2)$ & $9.5(25.8)$ & $\mathrm{A}=\mathrm{B}=\mathrm{C}$ & 0.121 \\
\hline Insomnia & $51.4(45.0)$ & $59.4(45.5)$ & $41.2(46.5)$ & $50.8(42.4)$ & $\mathrm{A}=\mathrm{B}=\mathrm{C}$ & 0.200 \\
\hline Loss of appetite & $25.1(39.1)$ & $37.0(44.6)$ & $17.6(33.1)$ & $18.2(34.7)$ & $\mathrm{B}=\mathrm{C}<\mathrm{A}$ & 0.033 \\
\hline Constipation & $28.4(39.7)$ & $38.4(42.7)$ & $11.8(25.8)$ & $30.9(41.9)$ & $\mathrm{B}<\mathrm{C}=\mathrm{A}$ & 0.010 \\
\hline Diarrhea & $9.0(25.7)$ & $11.6(30.0)$ & $4.9(20.3)$ & $9.5(24.7)$ & $\mathrm{A}=\mathrm{B}=\mathrm{C}$ & 0.513 \\
\hline Financial difficulties & $42.1(44.2)$ & $41.3(41.7)$ & $25.5(35.8)$ & $42.1(44.2)$ & $\mathrm{A}=\mathrm{B}=\mathrm{C}$ & 0.153 \\
\hline
\end{tabular}

Note. ${ }^{*}$ Scheffe's comparison; ${ }^{* *}$ ANOVA test; ${ }^{* * *}$ Higher score represents better score; ${ }^{* * * *}$ Higher score represents worse score; $\mathrm{min} /$ day = minutes per day; PA = Physical activity; $\mathrm{CT}=$ Chemotherapy; RT = Radiotherapy; HMT = Hormone Therapy. 
Table 3

Association between total physical activity, fatigue and quality of life of breast cancer patients according to the adjuvant treatment in CEPON. Florianópolis - SC. $(n=122)$

\begin{tabular}{|c|c|c|c|c|c|c|}
\hline \multirow{3}{*}{ Variables } & \multicolumn{6}{|c|}{ Total Physical Activity } \\
\hline & \multicolumn{3}{|c|}{ Unadjusted } & \multicolumn{3}{|c|}{ Adjusted* } \\
\hline & Beta & CI 95\% & $\mathrm{P}$ value & Beta & CI 95\% & P value \\
\hline \multicolumn{7}{|l|}{ Fatigue } \\
\hline Total & -0.42 & -3.37 a 2.53 & 0.778 & -0.26 & -3.28 a 2.75 & 0.863 \\
\hline Behavioral & -0.58 & -3.26 a 2.13 & 0.663 & -0.56 & -3.26 a 2.13 & 0.679 \\
\hline Affective & -1.84 & -4.27 a 0.60 & 0.139 & -1.81 & -4.28 a 0.65 & 0.148 \\
\hline Psychologic/Sensory & 0.81 & -2.18 a 3.80 & 0.594 & 1.09 & -1.92 a 4.10 & 0.476 \\
\hline \multicolumn{7}{|l|}{ EORTC-C30 } \\
\hline EORTC-C30 & -0.04 & -0.37 a 0.29 & 0.020 & -0.08 & -0.40 a 0.24 & 0.617 \\
\hline Global health status*** & 0.40 & 0.01 a 0.79 & 0.045 & 0.37 & -0.02 a 0.76 & 0.060 \\
\hline Functional scale ${ }^{* * *}$ & 0.51 & 0.12 a 0.91 & 0.011 & 0.52 & 0.13 a 0.90 & 0.009 \\
\hline Physical function & 0.19 & -0.03 a 0.42 & 0.092 & 0.17 & -0.05 a 0.40 & 0.132 \\
\hline Role performance & 0.07 & -0.18 a 0.32 & 0.570 & 0.04 & -0.21 a 0.29 & 0.758 \\
\hline Emotional function & 0.08 & -0.16 a 0.33 & 0.518 & 0.07 & -0.17 a 0.32 & 0.548 \\
\hline Cognitive function & 0.31 & 0.03 a 0.58 & 0.030 & 0.31 & 0.03 a 0.59 & 0.028 \\
\hline Social function & -0.38 & -0.74 a -0.02 & 0.036 & -0.30 & -0.66 a 0.07 & 0.116 \\
\hline Symptomatic scale & -0.35 & -0.58 a -0.12 & 0.003 & -0.31 & -0.55 a -0.08 & 0.008 \\
\hline Fatigue & -0.20 & -0.52 a 0.12 & 0.209 & -0.10 & -0.43 a 0.23 & 0.537 \\
\hline Nausea and vomit & -0.20 & -0.41 a 0.02 & 0.070 & -0.15 & -0.37 a 0.06 & 0.543 \\
\hline Pain & -0.06 & -0.38 a 0.24 & 0.668 & -0.02 & -0.33 a 0.29 & 0.908 \\
\hline Dyspnea & 0.08 & -0.11 a 0.27 & 0.410 & 0.10 & -0.08 a 0.29 & 0.275 \\
\hline Insomnia & -0.24 & $-0.45 a-0.02$ & 0.029 & -0.19 & -0.40 a 0.03 & 0.087 \\
\hline Loss of appetite & -0.02 & -0.24 a 0.19 & 0.821 & -0.00 & -0.21 a 0.21 & 0.994 \\
\hline Constipation & 0.02 & -0.31 a 0.35 & 0.900 & 0.04 & -0.29 a 0.36 & 0.816 \\
\hline Diarrhea & -0.05 & -0.25 a 0.16 & 0.638 & -0.04 & -0.26 a 0.17 & 0.680 \\
\hline
\end{tabular}

Note. CI - Confidence interval; ${ }^{*}$ Adjusted for age and type of treatment; ${ }^{* *}$ Higher score represents better score; ${ }^{* * * *}$ Higher score represents worse score.

\section{DISCUSSION}

This study aimed to compare the physical activity, fatigue and quality of life of patients during chemotherapy, radiotherapy and hormone therapy for breast cancer, as well as to investigate the association between these variables. The results showed that, in the comparison between the types of treatment, the patients in the hormone therapy presented a higher walking time and total physical activity. In the quality of life, only the symptomatic scale showed a difference between the types of treatment, and the worst scores were observed in patients on chemotherapy. For fatigue, a worse score was identified among radiotherapy patients. Regarding the association between variables (physical activity, fatigue and quality of life), the increase in physical activity was associated with a better quality of life in social function, physical function and fatigue in these patients, regardless of the type of treatment or age.

It is known that physical activity is beneficial for breast cancer patients both before and after diagnosis, decreasing cancer-specific mortality, as well as, for all causes (Zhong et al., 2014). The results of the present study indicated that the patients in hormone therapy are the ones that practice more physical activity, with greater walking times and total physical activity, when compared to those who were in chemotherapy and radiotherapy. The hormone therapy is a type of treatment aimed only to patients who present the hormone receptor positive, and this category of treatment lasts on average five years (Christinat, Lascio, \& Pagani, 2013). Currently, patients are in a period of return to their routine activities, unlike what happens during the period of chemotherapy and radiotherapy, in which they move away from their professional and leisure activities (Martins et al., 2009) possibly due to the side effects of these types of treatment.

The period of clinical treatment may be a factor that alters the level of moderate to vigorous physical activity practice in patients with breast cancer (Kwan et al., 2012). The patients undergoing hormone therapy are the 
ones who are most in treatment in the physiotherapy in this study. This may help in encouraging the practice of physical activity, since physical therapy can minimize the side effects of hormone therapy such as arthralgia and pain (Nyrop, et al. 2017) making these patients feel safer for the practice of physical activity.

Patients undergoing chemotherapy and radiotherapy had similar means of physical activity, and were significantly different from patients in hormone therapy. The same occurred in the study of Tonosaki and Ishkawa (2014), during the chemotherapy treatment. Even one year after treatment chemotherapy promotes a decrease in the level of physical activity when compared to other types of treatments (Hong et al., 2007; Lahart, Metsios, Nevill, \& Camicheal, 2014). The same is observed in patients that were undergoing radiotherapy (Charlier et al., 2012), which can be probably due to the side effects of these two types of treatment.

Chemotherapy is also associated with increased sedentary behavior by patients (Kwan et al., 2012), due to specific symptoms, especially fatigue, and in some cases, the longer the sedentary time, the greater the severity of fatigue (Almeida, Guerra, \& Filgueiras, 2011; MansanoSchlosser \& Ceolim, 2014; Phillips, 2016). During radiotherapy, a decrease in inspiratory capacity and vital capacity may occur, interfering with lung volume and respiratory muscle strength, affecting the patient's lung function (Schettino, Jotta, \& Cassali, 2010), which may hamper the practice of physical activity during this period, justifying in the present study, the lower time practice of physical activity for these patients in chemotherapy and radiotherapy.

Regarding the quality of life in the comparison between the types of treatment, no difference was found in the functional scale, as well as in the global health scale. The mean scores on these scales were similar, and one of the possibilities for this finding is that the whole period of adjuvant treatment can influence the functional scale, since the patients has emotional, cognitive and social issues and it can be not only influenced by one type of clinical treatment or another. Another factor that can influence the scales and differentiate them is the type of surgery, if it was radical or conservative (Sun et al., 2014; Veiga et al., 2010), however, this factor did not present a significant difference between the treatment types of the present study.

On the symptomatic scale, patients on chemotherapy had worse scores on the subscale's nausea and vomiting, pain and loss of appetite. The adverse effects of chemotherapy are divided into two groups: acute, which begin minutes after the administration of the antineoplastic agents and persist for a few days, and late, appearing weeks or months after their infusion (Roque \& Forones, 2006). These collateral effects produced by the treatments leave lasting sequelae, compromising several biological systems (Battaglini, Bottaro, Campbell, Novaes, \& Simão, 2004), affecting in general the quality of life of these patients. Like the results of the present study, Neris, Magnabosco, Amaral, Ribeiro and dos Anjos, (2016), who accompanied patients during chemotherapy, also pointed out an increase in the presence and intensity of pain during the chemotherapy treatment. Most of these patients suffer from post-treatment symptoms such as nausea, vomiting, insomnia, pain, loss of appetite and fatigue (Adamsen et al., 2009), as well as those reported by the present study. It is important to emphasize that patients undergoing chemotherapy were also the ones that had lower time of physical activity, which may be influenced by these issues of side effects, evidenced by the worse scores in the symptomatic scale of quality of life.

When the constipation subscale was observed, the worst scores were for the patients who were in the treatment of radiotherapy, since these women take high doses of opioids that lead to intestinal constipation and can generate physical and psychological discomforts, affecting their entire quality of life (Mercadante, Ferrera, \& Casuccio, 2017), justifying the findings of the present study.

Patients on chemotherapy also reported greater presence of fatigue. Fatigue is one of the most frequent manifestations being present in $75 \%$ to $95 \%$ of cases in cancer patients undergoing treatment with chemotherapy (Almeida et al., 2011, Mansano-Schlosser \& Ceolim, 2014). The relationship between 
chemotherapy and fatigue was cited in the study by Machado and Sawada (2008), in which increased fatigue was associated with chemotherapeutic treatment, as well as in the study by Mansano-Schlosser and Ceolim (2014), showing consequences in the daily life activities due to fatigue during chemotherapy treatment, corroborating the results of the present study, in which the patients in the chemotherapy reported greater perception of fatigue.

When investigating the association between physical activity, quality of life and fatigue, after adjusting for age and type of treatment, it was found that increase the daily time of physical activity is associated with an improvement in the physical function and social function of the quality of life. Some studies also reveal a relationship between the practice of physical activity with better quality of life and the physiological effects and social function in patients with breast cancer (Hong et al., 2007; Smith et al., 2009; Seixas, Kessler, \& Frison, 2010; Neto, Moreira, Resende, \& Ferreira, 2012; Mohammadi et al., 2013; Mason et al., 2013; Grabenbauer, Gradenbauer, Lengenfelder, Gradenbauer, e Distel, 2016; Steindorf et al. 2014; Leach et al., 2016).

For the symptomatic scale, in the same way, the daily time increase in physical activity was related to the reduction in the presence of fatigue. This fact is due to the reduction of the side-effects of the treatment promoted by the practice of physical activity (Hong et al., 2007). Similarly, the study by Phillips and Mcauley (2013), pointed out a relation between the practice of physical activity and the improvement of the symptoms of fatigue. Still, according to the study by Alfano, Ginsburg, and Kingery (2007), patients who remained active after 39 months of diagnosis had lower levels of fatigue and body pain, as well as improved functional capacity. Basen-Engquist, Hughes, Perkins, Shinn, and Taylor (2008) also observed improvement in functional capacity and lower levels of fatigue associated with physical activity. In the same way, the results of the present study evidenced such findings, thus, physical activity can be approached as a support to face cancer treatment and minimize its deleterious effects.

In view of the results obtained by the present study, it is understood that the practice of physical activity, even during clinical treatment, can be a determining factor for improving the quality of life and reducing fatigue in this period, minimizing the adverse effects from chemotherapy, radiotherapy and hormone therapy. In addition, the benefits obtained by the practice of physical activity during the treatment can last even after this phase; this highlights the importance of stimulating and providing the practice of physical activity during the treatment for breast cancer patients as a factor driving the improvement of health and coping with the disease. The recommendations for regular practice are at least 150 minutes of moderate physical activity per week or 75 minutes for vigorous intensity activities and suggests resistance training twice a week to improve physical health (Schmitz et al., 2010). Health professionals working in the oncology area should encourage the practice of physical activity for these patients, regardless of the type of treatment or age.

The present study showed some limitations, among them, the sample size, the cross-sectional design and the fact that the clinical information was collected through self-report. However, these limitations do not totally affect the internal validity of the study, since it was possible to observe statistically significant differences between the treatment groups and measures of bias control were introduced, both in planning, data collection and analysis. All the information was collected by qualified and trained professionals for this purpose and through instruments validated for this population. In the analysis, measures of control of possible confounding variables were used. 


\section{CONCLUSION}

Regarding the comparisons of physical activity during clinical treatment, it can be observed that the patients in the hormone therapy are those who presented the most time of practice, followed by the patients in the radiotherapy and chemotherapy. In the quality of life, on the symptomatic scale, the patients in the chemotherapy presented worse scores, as well as in the fatigue. It is understood that the period of chemotherapy, has presented significant side effects that imply in consequences in the quality of life and physical activity of these patients.

Associations were identified between the daily time increase in the practice of physical activity and the improvement in the patients' quality of life, regardless of the type of treatment and age. The need for intervention projects that incorporate the practice of physical activity during the treatment period is highlighted, since it is the period of greatest side effects. And given the positive results of physical activity, health professionals working with this population should be attentive to the needs and new possibilities of intervention, so that the patients have a better and faster recovery.

\section{Acknowledgments:}

Nothing to declare.

\section{Conflict of interests:}

Nothing to declare.

\section{Funding:}

This study was financed in part by the Coordenação de Aperfeiçoamento de Pessoal de Nível Superior - Brasil (CAPES) - Finance Code 001

\section{REFERENCES}

Aaronson, N. K., Ahmedzai, S., Bergman, B., Bullinger, M., Cull, A., Duez, N. J., Filiberti, A., ... \& de Haes J. C. (1993). The European Organization for Research and Treatment of Cancer QLQ-C30: A quality-of-life instrument for use in international clinical trials in oncology. Journal of the National Cancer Institute, 85(5), 365-376.

Adamsen, L., Quist, M., Andersen, C., Moller, T., Herrstedt, J., Kronborg, D., Baadsgaard, M.T., ... \& Rorth, M. (2009). Effect of a multimodal high intensity exercise intervention in cancer patients undergoing chemotherapy: randomized controlled trial. British Medical Journal, 229(7726), 1-11. doi: 10.1136/bmj.b3410

Alfano, C. A., Ginsburg, G. S., \& Kingery, J. N. (2007). Sleep-related problems among children and adolescents with anxiety disorders. Journal of the American Academy of Child and Adolescent Psychiatry, $46(2)$, 224-232. doi:10.1097/01.chi.0000242233.06011.8e

Almeida, T. R., Guerra, M. R., \& Filgueiras, M. S. T. (2012). Repercussões do câncer de mama na imagem corporal da mulher: uma revisão sistemática. Revista de Saúde Coletiva, 22(3), 10031029. doi: 10.1590/S0103-73312012000300009

American Cancer Society. 82105). Global Cancer Facts $\mathcal{E}$ Figures (3rd Edition). Atlanta: American Cancer Society.

Andrade, A. N., \& Duarte, T. P. (2003). Enfrentando a mastectomia: análise dos relatos de mulheres mastectomizadas sobre questões ligadas à sexualidade. Estudos de Psicologia, 8(1), 155-163. doi: 10.1590/S1413-294X2003000100017

Anjos, A. C., Paiva, L., Sales, C. A.C., \& Scandiuzzi, D. (2001). Qualidade de vida de mulheres tratadas de câncer de mama: funcionamento social. Revista brasileira de cancerologia, 47(3), 263-72.

Basen-Engquist, K., Hughes, D., Perkins, H., Shinn, E., \& Taylr, C. C. (2008). Dimensions of Physical Activity and their Relationship to Physical and Emotional Symptoms in Breast Cancer Survivors. Journal of Cancer Survivorship, 2(4), 253-261. doi: 10.1007/s11764-008-0067-9

Batista, R. F., Carneiro, P. F. P., Sampaio, S., Silva, E. C. S., Silva, L. F., \& Silva, M. (2014). Câncer de mama e qualidade de vida durante o tratamento radioterápico. Ciências Biológicas e da Saúde, 1(3), 85-93.

Battaglini, C. L., Bottaro, M., Campbell, J. S., Novaes, J., \& Simão, R. (2004). Atividade física e níveis de fadiga em pacientes portadores de câncer. Revista Brasileira de Medicina do Esporte, 10(2), 98104. doi: 10.1590/S1517-86922004000200004

Bezerra, K. B., Chein, M. B. C., Ferreira, P. R., Maranhão, J. K. P., Mochel, E. G., Ribeiro, N. L., \& Silva, D. S. M. (2013). Qualidade e vida de mulheres tratadas de câncer de mama em uma cidade do nordeste do Brasil. Revista Ciência \& saúde coletiva, 18(7), 1933-1941. doi: 10.1590/S1413-81232013000700008

Bleijemberga, G., Servaes, P., \& Verhagenb, C. (2002). Fatigue in cancer patients during and after treatment: prevalence, correlates and interventions. European Journal of Cancer, 38(1), 27-43.

Boing, L., Guimarães, A. C. A., Reis, N. M., \& Ribovski, M. (2016). Atividade física após o diagnóstico do câncer de mama: Revisão sistemática. Motricidade, 12(2), 155-166.

Bromberg, S., Katz, A., Saad, E. D., Simom, S. D. (2002). Inibidores da aromatase no câncer de mama: da doença metastática ao tratamento 
adjuvante. Revista Brasileira de Cancerologia, 48(4), 555-567.

Buffart, L., Brug, J., Ross, W., Chinapaw, M., JoeskstraWeebers, J., Knol, D., Korstjens, I., ..., \& Van Weert, E. (2012). How does exercise improve câncer survivors' quality of life? Journal of Sports Science and Medicine, 15, 333-334.

Cardoso, F. M. C., Nicolussi, A. C., Okino, L., \& Sawada, N. O. (2009). Avaliação da qualidade de vida de pacientes com câncer submetidos à quimioterapia. Revista da Escola de Enfermagem USP, 43(3), 581-587. doi: 10.1590/S008062342009000300012

Charlier, C., Van Hoof, E., Paulwels, E., Lechner, L., Spittaels, H., Bourgois, J., \& de Beourdeaudhuij. (2012). Treatment-related and psychosocial variables in explaining physical activity in women three weeks to six months post-treatment of breast cancer. Patient Education and Counseling, 89(1), 171-177. doi: 10.1016/j.pec.2012.06.029

Christinat, A., Di Lascio, S., \& Pagani, O. (2013). Hormonal therapies in young breast cancer patients: when, what and for how long? Journal of Thoracic Dissease, 5(1), 36-46. doi: 10.3978/j.issn.2072-1439.2013.05.25

Faul, F., Erdfelder, E., Lang, A.G., \& Buchner, A. (2007). G*Power 3: a flexible statistical power analysis program for the social, behavioral, and biomedical sciences. Behavior Research Methods, 39(2), 175-191. doi: 10.3758/BF03193146

Galanti, G., Klika, R., \& Stefani, L. (2017). Clinical Implementation of exercise guidelines for câncer patients: adaptation of ACSM's guidelines to the Italian Model. Journal of Funcional Morphoogy and Kinesiol, 2(4), 1-17. doi: 10.3390/jfmk2010004

Galvão, D. A., Hayes, S. C., Newton, R. U., \& Spence, R. R. (2009). Australian association for exercise and sports Science position stand: optimising câncer outcomes through exercise. Journal of Sports Science And Medicine, 12(4), 428-434. doi: 10.1016/j.jsams.2009.03.002

Grabenbauer, A., Grabenbauer, A. J., Lengenfelder, R., Grabenbauer, G. G., \& Distel, L. V. (2016). Feasibility of a 12-month-exercise intervention during and after radiation and chemotherapy in cancer patients: impact on quality of life, peak oxygen consumption, and body composition. Radiation Oncology, 11, 42. doi: 10.1186/s13014016-0619-5

Hong, S., Bardwell, W. A., Natarajan, L., Flatt, S. W., Rocj, C. L., Newman, V. A., Madlensky, L., ... \& Pierce, J. P. (2007). Correlates of physical activity level in breast cancer survivors participating in the Women's Healthy Eating and Living (WHEL) Study. Breast Cancer Research and Treatment, 101(2), 225-232. doi: 10.1007/s10549-0069284-y

Instituto Brasileiro de Geografia e Estatística. (2010). Projeção da população do Brasil. Disponível em: http//www.ibge.gov.br. Acesso em: 13 de outubro de 2014.
Instituto Nacional de Cancer José Alencas Gomes da Silva. (2012). ABDC do câncer: abordagens básicas para o controle do câncer.

Instituto nacional de câncer Jose de Alencas Gomes da Silva. (2015). Estimativa 2016: incidência de câncer no Brasil.

Instituto Nacional de Câncer. (2014). Estimativas 2014 de incidência de mortalidade câncer no Brasil.

Kwan, M. L., Sternfeld, B., Ergas, I. J., Timperi, A. W., Roh, J. M., Hong, C.C., ... \& Kushi, L. H. (2012). Change in Physical Activity During Active Treatment in a Prospective Study of Breast Cancer Survivors. Breast Cancer Research and Treatment. 131(2), 679-690. doi: 10.1007/s10549-011-1788-4

Lahart, I. M., Metsios, G. S., Nevill, A. M., \& Carmichael, A. R. (2014). Physical Activity Levels in Women Attending Breast Screening, Receiving Chemotherapy and Post-Breast Cancer Treatment; A Cross-Sectional Study. International Journal of Environmental Research and Public Health, 11(5), 5487-5496. doi: 10.3390/ijerph110505487

Leach, A. M., Ammar, N., England, D. N., Remigio, L. M., Kleinberg, B., \& Verschuere, B. J. (2016). Less ir more? Detecting lies in veiled witnesses. Law and Human Behavior, 40(4), 401-410, doi: 10.1037/lhb0000189

Lôbo, S. A., Fernandes, A. F. C., Almeida, P. C., Carvalho, C. M. L., \& Sawada, N. O. (2014). Qualidade de vida em mulheres com neoplasias de mama em quimioterapia. Acta Paulista de Enfermagem, 27(6), 554-559. doi: 10.1590/19820194201400090

Macêdo, G. D. N., Lucena, N. M. G., Soares, L. M. M., Rocha, P. O. A., Gutièrrez, C. V., \& López, M. C. B. (2011). Influência do Estilo de Vida na Qualidade de Vida de Mulheres com Câncer de Mama. Revista Brasileira de Ciências da Saúde, 14(4), 13-18.

Machado, S. M., \& Sawada, N. O. (2008). Avaliação da qualidade de vida de pacientes oncológicos em tratamento quimioterápico adjuvante. Texto $\mathcal{E}$ Contexto - Enfermagem, 17(4), 750-757. doi: 10.1590/S0104-07072008000400017

Mansano-Schlosser, T. C., \& Ceolim, M. F. Fadiga em idosos em tratamento quimioterápico. Revista Brasileira de Enfermagem, 67(4), 623-629. doi: 10.1590/0034-167.2014670419

Martins, L. C, Ferreira Filho, C., Del Giglio, A., Munhoes, D. A, Trevizan, L. L. B, Herbst, L. G, ... \& Pachon, S. C. (2009). Desempenho profissional ou doméstico das pacientes em quimioterapia para câncer de mama. Revista da Associação Médica Brasileira; 55(2), 158-62. doi: 10.1590/S0104-42302009000200019

Mason, C., Alfano, C. M., Smith, A.W., Wang, C. Y., Neuhouser, M. L., Duggan, C., Bernsteins, L., ... \& McTiernan, A. (2013). Long-term physical activity trends in breast cancer survivors. Cancer Epidemiology, Biomarkers \& Prevention, 22(6), 
1153-1161. doi: 10.1158/1055-9965.EPI-130141

Matsudo, S., Araújo, T., Matsudo, V., Andrade, D., Andrade, E., Oliveira, L. C., \& Braggion, G. (2001). Questionário Internacional de Atividade Física (IPAQ): Estudo de Validade e Reprodutibilidade no Brasil. Revista Brasileira de Atividade Física \& Saúde, 6(2), 1-14.

Mercadante, S., Ferrera, P., \& Casuccio, A. (2011). Effectiveness and tolerability of amidotrizoate for the treatment of constipation resistant to laxatives in advanced cancer patients. Journal of Pain and Symptom Management, 41(2), 421-425. doi: 10.1016/j.jpainsymman.2010.04.022

Michels, F. A. S., Latorre, M. R. D. O., \& Maciel, M. S. (2013). Validity, reliability and understanding of the EORTC-C30 and EORTC-BR23, quality of life questionnaires specific for breast cancer. Revista Brasileira de Epidemiologia, 16(2), 352-363. doi: 10.1590/S1415-790X2013000200011.

Mohammadi, S., Sulaiman, S., Koon, P. B., Amani, R., Hosseini, S. M. (2013). Impact of healthy eating practices and physical activity on quality of life among breast cancer survivors. Asian Pacific Journal of Cancer Prevention, 14(1), 481-487. doi: 10.7314/APJCP.2013.14.1.481

Mota, D. D. C. F., Pimenta, C. A. M., \& Piper, B. F. (2009). Fatigue in Brazilian cancer patients, caregivers, and nursing students: a psychometric validation study of the Piper Fatigue ScaleRevised. Supportive Care in Cancer, 17(6), 645-652. doi: 10.1007/s00520-008-0518-x

Neris, R. R., Magnabosco, P., Amaral, P. A., Ribeiro, M. A., \& dos Anjos, A. C. Y. (2016). Indução da dor pelo quimioterápico docetaxel em mulheres com câncer de mama. Acta Paulista de Enfermagem, 29(4), 397-404. doi: 10.1590/19820194201600055

Neto, M. S., Moreira, J. R., Resende, V., \& Ferreira, L. M. (2012). Nível de atividade física em mulheres mastectomizadas e submetidas a reconstrução mamária. Revista Brasileira de Cirurgia Plástica, $27(4)$, 556-561. doi: 10.1590/S198351752012000400015

Nyrop, K. A., Callahan, L. F., Cleveland, R. J., Arbeeva, L. L., Hackney, B. S., \& Muss, H. B. (2017). Randomized Controlled Trial of a Home-Based Walking Program to Reduce Moderate to Severe Aromatase Inhibitor-Associated Arthralgia in Breast Cancer Survivors. The Oncologist, 22(10), 1238-1249. doi: 10.1634/theoncologist.20170174

Pardini, R., Matsudo, S., Araújo, T., Matsudo, V., Andrade, E., Braggion, G., Andrade, D., ... \& Raso V. (1997). Validation of the international physical activity questionnaire (IPAQ): pilot study in brazilian young adults. Medicine \& Science in Sports \& Exercise, 29(6), 5-9.

Phillips, S. M., Lloyd, G. R., Awick, E. A., \& McAuley, E. (2016). Correlates of objectively measured sedentary behavior in breast cancer survivors,
Cancer Causes \& Control, 27(6), 787-795. doi: $10.1007 / \mathrm{s} 10552-016-0756-z$

Phillips, S. M., \& Mcauley, E. (2013). Physical Activity and Fatigue in Breast Cancer Survivors: A Panel Model Examining the Role of Self-efficacy and Depression. Cancer Epidemiology, Biomarkers $\mathcal{E}$ Prevention, 22(5), 773-781. doi: 10.1158/10559965.EPI-12-0983

Piper, B. F., Dibble, S. L., Dodd, M. J., Weiss, M. C., Slaughter, R. E., \& Paul, S. M. (1998). The revised Piper Fatigue Scale: psychometric evaluation in women with breast cancer. Oncology Nursing Forum, 25(4), 677-684. doi: 10.1007/s00520-008-0518-X

Roque, V. M. N., \& Forones, N. M. (2006). Avaliação da qualidade de vida e toxicidades em pacientes com câncer colorretal tratados com quimioterapia adjuvante baseada em fluoropirimidinas. Arquivos de Gastroenterologia, 43(2), 94-101. doi: 10.1590/s000428032006000200007

Schettino, R. C., Jotta, L. M. G. N., \& Cassali, G. D. (2010). Função pulmonar em mulheres com câncer de mama submetidas à radioterapia: um estudo piloto. Fisioterapia e Pesquisa, 17(3), 24852. doi: 10.1590/S1809-29502010000300011

Schmitz, K. H., Courneya, K. S., Matthews, C., Demark-Wahnefried, W., Galvão, D. A., Pinto, B. M., Irwin, M. L., ... \& Shwartz, A. L. (2010). American College of Sports Medicine roundtable on exercise guidelines for cancer survivors. Medicine \& Science in Sports \& Exercise, 42 (7), 14091426. doi: 10.1249/MSS.0b013e3181e0c112

Seixas, R. J., Kessler, A., \& Frison, V. B. (2010). Atividade Física e Qualidade de Vida em Pacientes Oncológicos durante o Período de Tratamento Quimioterápico. Revista Brasileira de Cancerologia, 56 (3), 321-330.

Smith, A. W., Alfano, C. M., Reeve, B. B, Irwin, M. L., Bernstein, L., Baumgarner, K., Bown, D., ... \& Ballard-Barbash, R. (2009). Race/Ethnicity, Physical Activity and Quality of Life in Breast Cancer Survivors. Cancer Epidemiology, Biomarkers E Prevention, 18(2), 656-663. doi: 10.1158/10559965.EPI-08-0352

Steindorf, K., Schmidt, M. E., Klassen, O., Ulrich, C. M., Oelmann, J., Habermann, N., Beckhove, P., ... \& Potthoff, K. (2014). Randomized, controlled trial of resistance training in breast cancer patients receiving adjuvant radiotherapy: results on cancer-related fatigue and quality of life. Annals of Oncology, 25(11), 2237-2243. doi: 10.1093/annonc/mdu374

Sun, Y., Kim, S. W., Heo, C. Y., Kim, D., Hwang, Y., \& Kang, E. (2014). Comparison of Quality of Life Based on Surgical Technique in Patients with Breast Cancer. Japanese Journal of Clinical Oncology, 44(1), 22-27. doi: 10.1093/jjco/hyt176

Tonosaki, A., \& Ishikawa, M. (2014). Physical activity and health status perception of breast cancer patients undergoing adjuvante chemotherapy. 
70 | L Boing, TB Fretta, MCS Vieira, LA Denig, A Bergmann, ACA Guimarães

European Journal of Oncology Nursing, 18(2), 132139. doi: 10.1016/j.ejon.2013.11.008

Veiga, D. N., Campos, F. S. M., Ribeiro, L. M., Junior, I. A., Filho, J. V., Juliano, Y., ... \& Ferreira, L.M. (2010). Mastectomy versus conservative surgical treatment: the impact on the quality of life of women with breast cancer. Revista Brasileira de Saúde Materno Infantil, 10(1), 51-57. doi: $10.1590 /$ S1519-38292010000100005
World Health Organization. (2014). Cancer country profelies.

Zhong, S., Jiang, T., Ma, T., Zhang, X., Tang, J., Chen, W., Lu, M., \& Zhao, J. (2014). Association between physical activity and mortality in breast cancer: a meta-analysis of cohort studies. European Journal of Epidemiology, 29(6), 391-404. doi: 10.1007/s10654-014-9916-1

All content of Journal Motricidade is licensed under Creative Commons, except when otherwise specified and in content retrieved from other bibliographic sources. 